\title{
Pericallosal Artery
}

National Cancer Institute

\section{Source}

National Cancer Institute. Pericallosal Artery. NCI Thesaurus. Code C33295.

A terminal branch of the anterior cerebral artery that runs in the pericallosal sulcus and branches to form the inferior and superior internal parietal arteries and precuneal artery supplying the cerebral cortex. 